\title{
Randomised controlled trial: comparing effects of metformin versus myoinositol versus metformin and myoinositol on ovarian functions and metabolic factors in polycystic ovarian syndrome
}

\author{
Shikha Singh Thakur ${ }^{1 *}$, Shaheen Anjum¹, S. S. Siddiqui ${ }^{2}$
}

${ }^{1}$ Department of Obstetrics and Gynecology, JNMCH, Aligarh Muslim University, Aligarh, Uttar Pradesh, India
${ }^{2}$ Department of Endocrinology, JNMCH, Aligarh Muslim University, Aligarh, Uttar Pradesh, India

Received: 07 April 2020

Accepted: 29 April 2020

*Correspondence:

Dr. Shikha Singh Thakur,

E-mail: shikhathakur26291@gmail.com

Copyright: (C) the author(s), publisher and licensee Medip Academy. This is an open-access article distributed under the terms of the Creative Commons Attribution Non-Commercial License, which permits unrestricted non-commercial use, distribution, and reproduction in any medium, provided the original work is properly cited.

\begin{abstract}
Background: Polycystic ovarian syndrome (PCOS) characterized by anovulation and features of hyperandrogenism (clinical or biochemical) and insulin resistance. Metformin and myoinositol being insulin sensitizers improve clinical and biochemical parameters. This study was done to compare the effects of these drugs on clinical features and biochemical profile.

Methods: A randomized, comparative, clinical study was conducted on 72 patients. The patients were randomized with the help of computer-generated random numbers and were allocated to either of the three treatment groups $\mathrm{A}, \mathrm{B}$ and C. Patients in group A received metformin $500 \mathrm{mg}$ TDS, group B received myoinositol $1000 \mathrm{mg}$ BD, group C received combination of metformin $500 \mathrm{mg}$ and myoinositol $550 \mathrm{mg}$ BD for 24 weeks. At first visit patients detailed history and baseline investigations were recorded. Follow up was done 24 weeks after start of therapy to assess the improvement in clinical and biochemical profile.

Results: There was significant improvement in menstrual irregularities, cutaneous manifestations, pregnancy rate, LH/FSH ratio, insulin sensitivity and HOMA-IR after 24 weeks of treatment in all three groups (p value $<0.05)$, although there was greater improvement in cases treated with combination of metformin and myoinositol than metformin and myoinositol alone.

Conclusions: The combination of metformin and myoinositol has resulted in more significant reduction in insulin resistance and improvement in metabolic and hormonal profile along with regularization of menstrual cycles and spontaneous conception than metformin and myoinositol alone.
\end{abstract}

Keywords: Insulin resistance, Metformin, Myoinositol, Polycystic ovarian syndrome

\section{INTRODUCTION}

Polycystic ovarian syndrome (PCOS) is one of the most common endocrinological disorders in women of reproductive age group with estimated prevalence of 5$10 \% .^{1}$ Several studies have reported prevalence rates of $7-10 \%$ in Indian population. ${ }^{2,3}$ This syndrome was first described by Stein and Leventhal in 1935. It is one of the major causes of primary amenorrhea and also a leading cause of infertility due to menstrual disorders. ${ }^{4}$
Anovulation (or oligo-ovulation) in women with PCOS is one of the commonest causes of infertility. ${ }^{5}$ High circulating androgen levels result in hirsutism and acne in women with PCOS. Other recognized associations of PCOS include acanthosis nigricans, increased tendency to develop type 2 diabetes, hypertension, dyslipidaemia in younger age group and endometrial carcinoma, breast carcinoma and metabolic syndrome in later life. Hence, PCOS is a syndrome of long-term consequences and not a disease of short-term effects. ${ }^{6}$ 
The Rotterdam ESRE/ASRM sponsored PCOS consensus workshop group 2004 gave three key features of which at least two must be present to fulfil the Rotterdam criteria for the diagnosis of PCOS: ${ }^{7}$

- Anovulation or oligo-ovulation with lesser than nine menstrual periods every 12 months

- Clinical or biochemical evidence of hyperandrogenism

- Minimum 12 small follicles measuring 2-9 $\mathrm{mm}$ in at least one ovary.

Other etiologies such as congenital adrenal hyperplasia, androgen secreting tumor, thyroid dysfunction and hyperprolactinemia must be excluded. ${ }^{8}$

In 2018 the CREPCOS (Centre for research excellence in polycystic ovary syndrome) in partnership with ESHRE and ASRM developed the evidence-based guideline for the assessment and management of PCOS to improve the quality of healthcare, health outcomes and quality of life of woman with PCOS.

Approximately $80 \%$ of obese women and $30-40 \%$ of lean women with PCOS have hyperinsulinemia due to insulin resistance. ${ }^{9}$ Despite its etiopathogenesis being elusive, insulin resistance appears to be the fundamental common pathway to disease in addition to genetic and environmental factors. Insulin directly promotes ovarian steroidogenesis, and inhibits liver release of the sex hormone binding globulin (SHBG) and production of insulin -like growth factor binding protein 1 (IGFBP-1). Increased concentrations of IGF-1 additionally promote ovarian release of androgens. So, insulin resistance and compensatory hyperinsulinemia appear to play a pathophysiological role in hyperandrogenism and PCOS. ${ }^{10}$

The severity of PCOS is also influenced by environmental factors like nutrition and lifestyle. ${ }^{11}$ Lifestyle modification and dietary advice is mandatory for all patients with PCOS prior to specific fertility treatment. Some studies have postulated that weight loss of only a few kilograms may induce ovulation. ${ }^{12-14}$

Ever since the establishment of diagnostic criteria, there has been resurgence of newer drugs aimed at correcting biochemical abnormalities and thereby restoring ovarian function. ${ }^{15}$

Insulin sensitizing agents increase tissue sensitivity to insulin and hence enhance insulin activity in PCOS women. Metformin, an oral biguanide is a time-tested drug in clinical practice. It was the first insulin sensitizing drug to be used in PCOS. Since first paper Velazquez et al, various studies have been performed on metformin treatment and even recent Cochrane analysis Tang et al. suggests that metformin is still beneficial in improving clinical pregnancy and ovulation rates. ${ }^{16}$
Myo-inositol is a new drug in the group of insulin sensitizers, which is supposedly safe due to their natural origin. ${ }^{17}$ A deficiency of inositol has been postulated as a key factor in the pathogenesis of PCOS. Isoform of inositol belongs to the vitamin B complex group. Myoinositol, which is optically inactive, is the only form of the nine cyclohexanols with known biological importance. D-chiro inositol and Myo-inositol accelerates glucose disposal and sensitize insulin action. ${ }^{17}$ It has also shown improvement in oocyte maturation, follicular milieu and outcome of ART in PCOS women. ${ }^{18}$

It has been postulated that both the drugs in combination may have additive effect in management of hyperinsulinemia in PCOS with the reduction in the doses of individual drugs to achieve similar efficacy.

This study was conducted with the aim to evaluate the effects of metformin, myoinositol and combination of metformin and myoinositol on ovarian function and metabolic derangements in cases of PCOS.

The objectives of this study were to evaluate the effect of these drugs on clinical outcome as fertility rate, regularization of menses and decrease in hyperandrogenic features and to compare the improvement in metabolic and hormonal parameters in women with PCOS.

\section{METHODS}

The present study was prospective, open label, randomized, comparative and interventional clinical trial conducted from August 2017 to august 2019 in the department of obstetrics and gynecology at JNMCH Aligarh after obtaining permission of institutional ethical committee. An informed consent was obtained from all the patients enrolled for the study.

\section{Inclusion criteria}

- $\quad$ All the females with PCOS of age group 15-40 years attended OPD of obstetrics and gynecology at JNMCH fulfilled the Rotterdam criteria and who had willingly given consent for this study.

\section{Exclusion criteria}

- Pregnancy

- Patients were already on other drug treatment for PCOS (like oral contraceptive pills) or already taking metformin or myo-inositol

- Deranged kidney or liver function tests

- Hyper prolactinemia

- Cushing's disease

- Congenital adrenal hyperplasia

- Androgen secreting neoplasia

- Thyroid disorders

- Known hypersensitivity to myoinositol

- Inability to come for follow-up. 
A total of 108 patients with PCOS were screened for this study. Out of these, 28 did not fulfil the predefined inclusion criteria of the study and 8 were not willing to give the informed consent, so they were excluded from the study. So final number of patients included in study were 72 . These 72 patients, enrolled in the study were randomized with the help of computer-generated random numbers and were allocated to either of the three treatment groups A, B and C. Of the 72 patients enrolled in the study, 24 patients were allotted in each group. Patients in Group A received metformin $500 \mathrm{mg}$ TDS, Group B received myoinositol $1000 \mathrm{mg}$ BD, Group C received combination of metformin $500 \mathrm{mg}$ and myoinositol $550 \mathrm{mg}$ BD for 24 weeks. 3 patients in Group A , 3 patients in Group B and 2 patients in Group C were lost till final follow-up and were dropped from the study and remaining 21 patients in Group A, 21 patients in Group B and 22 patients in Group C completed the treatment successfully (Figure 1).

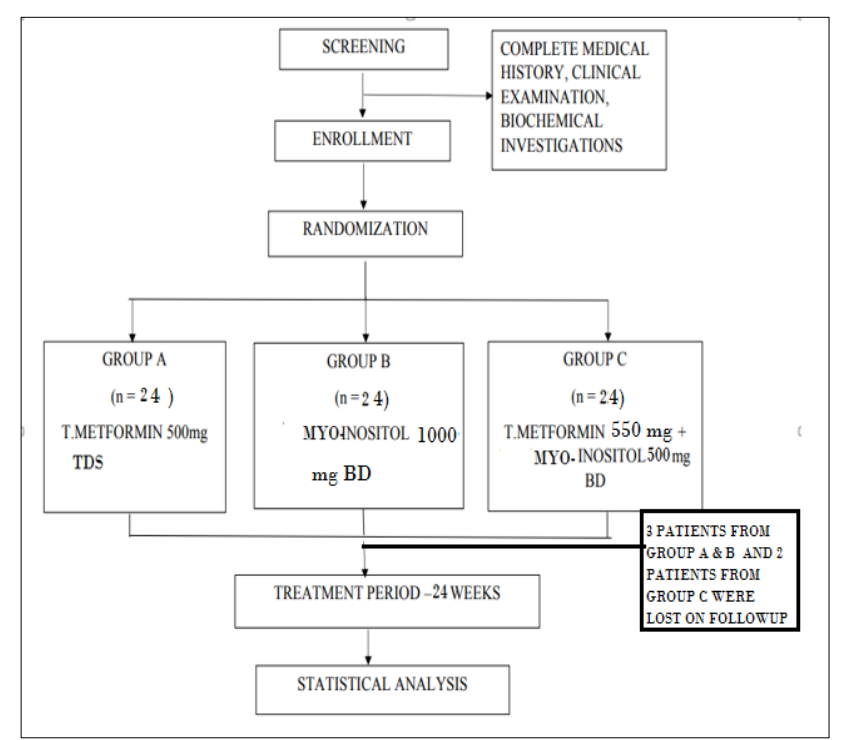

Figure 1: Methodology for the present trial.

At first visit, a detailed history and physical examination were done as per designed proforma. Examination included general examination (BP, weight, height) and calculation of BMI, waist/hip ratio along with examination for androgenic features (Hirsutism and acne). Baseline Investigations as fasting blood sugar, fasting insulin, HOMA-IR index were done. Transabdominal ultrasound (TAS) was done in unmarried young patients whereas transvaginal ultrasound (TVS) was done for patients who presented with Infertility. Thereafter patients were explained about diet and lifestyle modification irrespective of the allotted group and prescribed medicines according to the allotted group.

Cases were reassessed at the end of 24 weeks of treatment for regularity of menstrual cycles, weight, BMI, improvement in cutaneous manifestations, HOMA-IR and spontaneous conception. Cut-off body mass index (BMI) with body fat as standard consensus statement for Indian population was considered i.e., normal BMI: 18.0$22.9 \mathrm{~kg} / \mathrm{m}^{2}$, overweight: $23.0-24.9 \mathrm{~kg} / \mathrm{m}^{2}$ Obesity: $>25$ $\mathrm{kg} / \mathrm{m}^{2} \mathrm{BMI} \geq 25$ was considered as obese. ${ }^{19}$ Hirsutism was clinically evaluated using the modified Ferriman-Galway score. Any score of greater than 8 was defined as hirsutism. ${ }^{20}$

Since there is no consensus on the cut-off value of HOMA-IR to define insulin resistance, cut-off value of HOMA-IR of $>2.5$ was accepted as definition of insulin resistance in this study. ${ }^{21-23}$

\section{Statistical analysis}

The data collected was analyzed statistically by computing the descriptive statistics viz., mean, SD, median, range and both intragroup and intergroup statistical analysis was evaluated by student " $t$ " test or any other test. 'p' values of less than 0.05 was considered statistically significant.

\section{RESULTS}

Of the 72 patients were enrolled in the study, 21 patients in Group A, 21 patients in Group B and 22 patients in Group C completed the treatment successfully. The baseline characteristics of the patients are tabulated in Table 1.

Table 1: Comparison of demographic profile of study subjects in three groups.

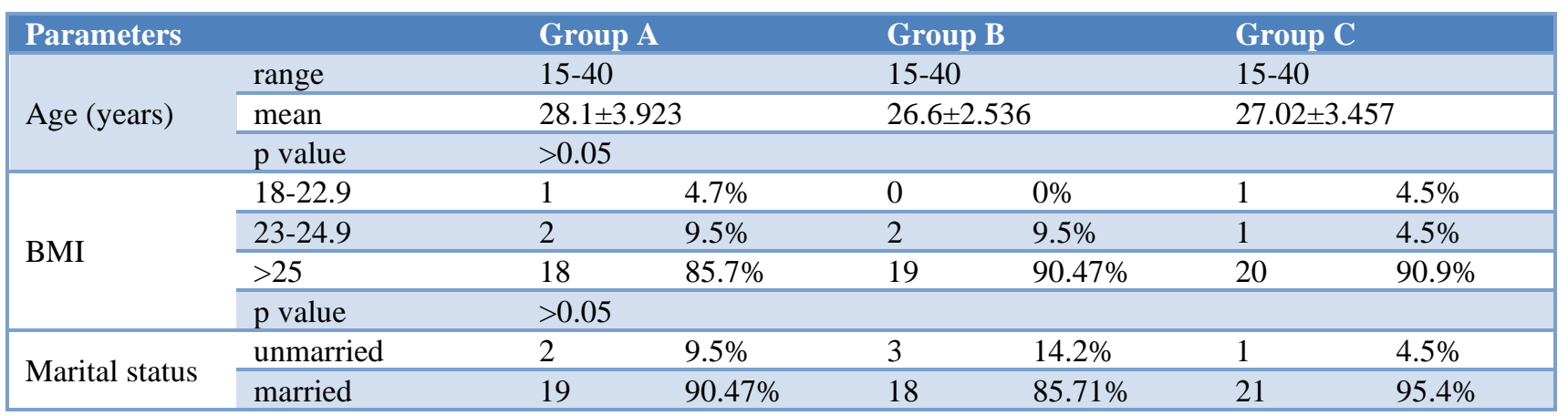


Table 2: Effect of therapy on clinical parameters.

\begin{tabular}{|c|c|c|c|c|c|c|}
\hline Parameters & Group A & & Group B & & Group C & \\
\hline & Baseline & $\begin{array}{l}24 \text { weeks after } \\
\text { treatment }\end{array}$ & Baseline & $\begin{array}{l}24 \text { weeks after } \\
\text { treatment }\end{array}$ & Baseline & $\begin{array}{l}24 \text { weeks after } \\
\text { treatment }\end{array}$ \\
\hline & & Improved & & Improved & & Improved \\
\hline $\begin{array}{l}\text { Menstrual } \\
\text { irregularity }\end{array}$ & $19 / 90.5 \%$ & $12 / 63.15 \%$ & $18 / 85.8 \%$ & $6 / 33.3 \%$ & $19 / 86.37 \%$ & $12 / 63.15 \%$ \\
\hline $\mathrm{p}$ value & & $<0.05$ & & $<0.05$ & & $<0.05$ \\
\hline Oligomenorrhea & $12 / 63.15 \%$ & $7 / 33.3 \%$ & $10 / 55.5 \%$ & $2 / 20 \%$ & $11 / 57.89 \%$ & $5 / 45.45 \%$ \\
\hline $\begin{array}{l}\text { Oligo- } \\
\text { hypomenorrhea }\end{array}$ & $4 / 21.05 \%$ & $2 / 50 \%$ & $3 / 16.66 \%$ & $1 / 33.3 \%$ & $5 / 26.3 \%$ & $4 / 80 \%$ \\
\hline Amenorrhea & $3 / 15.78 \%$ & $3 / 100 \%$ & $5 / 27.7 \%$ & $3 / 60 \%$ & $3 / 15.7 \%$ & $3 / 100 \%$ \\
\hline $\mathrm{p}$ value & $>0.05$ & & & & & \\
\hline Skin manifestation & $15 / 71.4 \%$ & $9 / 60 \%$ & $14 / 66.6 \%$ & $3 / 21.42 \%$ & $18 / 81.8 \%$ & $11 / 61.1 \%$ \\
\hline Acne & $5 / 33.3 \%$ & $3 / 60 \%$ & $4 / 28.4 \%$ & $1 / 25 \%$ & $6 / 33.3 \%$ & $3 / 50 \%$ \\
\hline $\mathrm{p}$ value & & $<0.05$ & & $>0.05$ & & $e<0.05$ \\
\hline Hirsutism & $10 / 66.6 \%$ & $6 / 60 \%$ & $10 / 71.4 \%$ & $2 / 20 \%$ & $12 / 66.6 \%$ & $8 / 66.7 \%$ \\
\hline $\mathrm{p}$ value & & $<0.05$ & & $>0.05$ & & $e<0.05$ \\
\hline $\mathrm{p}$ value & $>0.05$ & & & & & \\
\hline BMI & $27.45 / 2.81$ & $25.15 / 2.78$ & $28.83 / 2.3$ & $27.07 / 2.70$ & $28.03 / 3.14$ & $25.56 / 3.081$ \\
\hline $\mathrm{p}$ value & & $<0.05$ & & $<0.05$ & & $<0.05$ \\
\hline $\mathrm{p}$ value & $>0.05$ & & & & & \\
\hline
\end{tabular}

Table 3: Effect of therapy on hormonal parameters.

\begin{tabular}{|c|c|c|c|c|c|c|}
\hline \multirow[t]{2}{*}{ Parameters } & \multicolumn{2}{|l|}{ Group A } & \multicolumn{2}{|l|}{ Group B } & \multicolumn{2}{|l|}{ Group C } \\
\hline & $\begin{array}{l}\text { Baseline } \\
\text { mean /SD }\end{array}$ & $\begin{array}{l}24 \text { weeks after } \\
\text { treatment mean/SD } \\
\text { p value }\end{array}$ & $\begin{array}{l}\text { Baseline } \\
\text { mean/SD }\end{array}$ & $\begin{array}{l}24 \text { weeks after } \\
\text { treatment } \\
\text { mean/SD p value }\end{array}$ & $\begin{array}{l}\text { Baseline } \\
\text { mean /SD }\end{array}$ & $\begin{array}{l}24 \text { weeks after } \\
\text { treatment mean } \\
\text { /SD p value }\end{array}$ \\
\hline $\begin{array}{l}\text { Fasting } \\
\text { blood sugar }\end{array}$ & $94.29 / 6.58$ & $88.16 / 4.87$ & $95.55 / 5.90$ & $88.44 / 5.20$ & $96.05 / 9.50$ & $89.23 / 4.66$ \\
\hline $\mathrm{p}$ value & & $<0.01$ & & $<0.01$ & & $<0.01$ \\
\hline $\begin{array}{l}\text { Fasting } \\
\text { insulin }\end{array}$ & $14.21 / 2.79$ & $11.19 / 2.16$ & $14.41 / 4.29$ & $11.19 / 3.10$ & $13.88 / 3.09$ & $10.75 / 2.27$ \\
\hline $\mathrm{p}$ value & & $<0.01$ & & $<0.01$ & & $<0.01$ \\
\hline HOMA-IR & $3.28 / 0.75$ & $2.42 / 0.53$ & $3.34 / 0.93$ & $2.38 / 0.58$ & $3.51 / 0.902$ & $2.56 / 0.54$ \\
\hline $\mathrm{p}$ value & & $<0.01$ & & $<0.01$ & & $<0.01$ \\
\hline $\mathrm{p}$ value & $>0.05$ & & & & & \\
\hline LH/FSH & $2.439 / 0.42$ & $1.305 / 0.22$ & $2.12 / 0.37$ & $1.22 / 0.24$ & $2.35 / 0.33$ & $1.21 / 0.21$ \\
\hline $\mathrm{p}$ value & & 0.002 & & 0.004 & & 0.0012 \\
\hline $\mathrm{p}$ value & $>0.05$ & & & & & \\
\hline
\end{tabular}

The mean age of the women in Group A was 28.1 \pm 3.923 years whereas in Group B it was $26.67 \pm 2.536$ years and $27.05 \pm 3.457$ years in Group $C$ i.e. mostly comprising of younger population. Most of the patients were observed to be overweight i.e. BMI >23. 91.2\% (n=58) were married and $8.8 \%(n=6)$ were unmarried. In the present study clinical presentation varied a wide range; most cases came with the complaint of weight gain followed by menstrual irregularity and then by infertility in all three groups. The history of weight gain was present in $85.71 \%, 85.6 \%$ and $90.9 \%$ cases in Group A, B and C respectively.
Table 2 shows effect of therapy on clinical parameters, $63.2 \%(\mathrm{n}=12), 33.3 \% \quad(\mathrm{n}=6)$ and $63.2 \% \quad(\mathrm{n}=12)$ cases developed regular cycle in group $\mathrm{A}, \mathrm{B}$ and $\mathrm{C}$ respectively after 24 weeks of treatment. The cycle length was decreased in oligomenorrhea patients whereas there was occurrence of spontaneous menses in all amenorrhea patients. There was statistically significant improvement in menstrual cycles after 24 weeks of treatment ( $p$ value $<0.05$ ) in all the groups. Although the effect of myoinositol therapy appear to be less on regularization of cycle, but the difference was not statistically significant among groups ( $\mathrm{p}$ value $>0.05$ ). 
Skin problems as acne and hirsutism were improved in $60 \%$ of cases in group A whereas $66.7 \%$ of hirsutism and $50 \%$ of acne cases showed improvement in Group C. But only $20 \%$ of cases with hirsutism and $25 \%$ cases with acne were improved in Group B. There was statistically significant improvement in acne and hirsutism cases in Group C and A (p value <0.05), but Group B did not show any significant improvement in cutaneous manifestations ( $\mathrm{p}$ value $>0.05$ )

There was statistically significant reduction in BMI in all three groups after 24 weeks but the reduction was not statistically significant between the groups. There was statistically significant improvement in insulin resistance as assessed with HOMA-IR in all three groups at the end of 24 weeks as compared to baseline values. In metformin group HOMA-IR decreased by 0.86 , in myoinositol group it decreased by 0.96 , while in combination of metformin and myoinositol it is decreased by 0.95 compared to baseline values after 24 weeks of therapy.

There was statistically significant improvement in hormonal parameters as assessed by changes in LH/FSH ratio with all cases over a period of 24 weeks. In metformin group LH/FSH ratio decreased by 1.134 , in myoinositol treated cases it was decreased by 0.9 and in metformin and myoinositol treated cases it was decreased by 1.14 as compared to baseline values.

In this study $28.84 \%(\mathrm{n}=15)$ cases of infertility conceived after 6months of treatment, of which $66.6 \% \quad(n=10)$ belonged to primary infertility and $33.3 \%(n=5)$ belonged to secondary infertility. The pregnancy rates were highest in Group C i.e. 35\% ( $n=7)$ followed by Group A was $31.3 \%(n=5)$ and then $18.7 \%(n=3)$ in Group B.

Table 4: Effect of therapy on pregnancy rate.

\begin{tabular}{|c|c|c|c|c|c|c|}
\hline Parameters & Group A & & Group B & & Group C & \\
\hline & Baseline & $\begin{array}{l}\text { Pregnancy } 24 \\
\text { weeks after } \\
\text { treatment }\end{array}$ & Baseline & $\begin{array}{l}\text { Pregnancy } 24 \\
\text { weeks after } \\
\text { treatment }\end{array}$ & Baseline & $\begin{array}{l}\text { Pregnancy } 24 \\
\text { weeks after } \\
\text { treatment }\end{array}$ \\
\hline Infertility & $16 / 76.19 \%$ & $5 / 31.3 \%$ & $16 / 76.19 \%$ & $3 / 18.7 \%$ & $20 / 90.9 \%$ & $7 / 35 \%$ \\
\hline $\mathrm{p}$ value & & $<0.05$ & & 0.05 & & $<0.05$ \\
\hline Primary & $12 / 75 \%$ & $3 / 25 \%$ & $11 / 68.75 \%$ & $3 / 27.3 \%$ & $14 / 70 \%$ & $4 / 28.57 \%$ \\
\hline Secondary & $4 / 25 \%$ & $2 / 50 \%$ & $5 / 31.3 \%$ & $0 / 00 \%$ & $6 / 30 \%$ & $3 / 50 \%$ \\
\hline
\end{tabular}

There was statistically significant improvement in pregnancy rates after 24 weeks of treatment in Groups A ( $p$ value $<0.05)$ and $C(p$ value $<0.05)$ of which Group $C$ was more. Whereas the improvement in fertility rate in Group B was not significant ( $\mathrm{p}$ value $>0.05$ ).

\section{DISCUSSION}

PCOS is a complex heterogenous endocrine disorder affecting woman of reproductive age group. It is the most common cause of female infertility due to endocrinological disorder and it is characterized by a combination of hyperandrogenism, chronic an-ovulation and irregular menstrual cycle. ${ }^{24}$ Patients with PCOS have multiple metabolic disturbances such as Diabetes, cardiovascular disorders, metabolic syndrome, dyslipidemia. This emphasizes the long term need for prevention of these morbidities. In about $50 \%$ of patients with PCOS, there are defects in insulin receptor and post receptor components of the insulin signaling pathway. ${ }^{25,26}$

Several trials showed that insulin sensitizing agents, such as myoinositol and metformin, are the first line pharmacological treatment to restore the ovulation hence normal menstrual cycles in women with PCOS. ${ }^{25,26}$
Which suggests that an end cellular defect of the precursor of IPG such as MI and DCI might trigger the compensatory hyperinsulinemia in most PCOS subjects.

Weight gain is one of the most common presenting complain of patients with PCOS. Nearly $87.5 \% \quad(n=56)$ patients presented with weight gain. When comparing weight in this study groups authors found that in groupA, $95.2 \%(n=20)$ of the patients were overweight (BMI >23). In Group B and C, percentage of patient's overweight were $99.8 \% \quad(n=21)$ and $95.4 \% \quad(n=21)$ respectively.

Dietary and lifestyle modification was advised to all the cases enrolled in the study irrespective of the groups. As there was no statistically significant difference in the mean BMI between all the groups at the first visit, all three groups were comparable. It reduced from $28.03 \pm 3.14$ before treatment to $25.56 \pm 3.08$ in Group $\mathrm{C}$ with mean reduction of $2.47+0.06$ in BMI. Whereas in Group B and C the observed mean BMI reduction was $2.3 \pm 0.03$ and $1.76 \pm 0.23$ respectively. Similarly, the mean waist to hip ratio (WHR) showed statistically significant reduction in all three groups after 24 weeks of therapy ( $p$ value <0.05). There was no statistically significant 
difference in BMI and WHR after 24 weeks of treatment between the groups ( $\mathrm{p}$ value $>0.05$ ). Hence, all groups were comparable before and after treatment. Whereas in study conducted by Chirania $\mathrm{K}$ et al, there was significant reduction in BMI in groups treated with myoinositol (Group A) $(\mathrm{p}=0.001)$ and metformin (Group B) $(\mathrm{p}=0.001)$ but not in group treated with combination of metformin and myoinositol (Group C) $(\mathrm{p}=0.687) .{ }^{27}$ Angik R et al showed significant BMI reduction in myoinositol group from 24.17 to 23.96 ( $\mathrm{p}$ value $<0.05$ ) and in metformin group from 23.3 to 23.2 ( $\mathrm{p}$ value $<0.05$ ) after 6 months of treatment. ${ }^{28}$

Menstrual irregularity was one of the most common presenting complain of PCOS. When comparing menstrual abnormality in this study groups authors found that in Group-A, $90.47 \%(n=19)$ cases where as in Group B and C, $85.71 \%(n=18)$ and $86.36 \%(n=19)$ cases were present respectively. Most of the patients presented with more than one clinical symptom. Amongst amenorrhea patients, spontaneous onset of menses was observed in $100 \%$ with metformin and combination therapy while $60 \%$ with myoinositol therapy. Many patients started menstruating within two months of treatment. Nearly $60 \%$ of patients showed regularization of cycles in oligomenorrhea. There was significant improvement in menstrual irregularities after 24 weeks of treatment in all three groups ( $\mathrm{p}$ value $<0.05$ ), although there was greater improvement in regularization of menses in cases treated with combination of metformin and myoinositol and metformin alone than with myoinositol alone but the difference was not statistically significant $(>0.05)$.

In the study conducted by Nagaria $T$ et al after 6 months of treatment with combination of metformin and myoinositol there was $100 \%$ spontaneous resumption of menses in amenorrhea cases, whereas $90.09 \%$ cases with oligomenorrhea attained regular menstrual cycles. ${ }^{29}$ In the study performed by Chirania et al, treatment of PCOS cases in three groups $(\mathrm{A}=$ myoinositol, $\mathrm{B}=$ metformin, $\mathrm{C}=$ myoinositol and metformin combination) for 6 months showed $66.6 \%, 15.78 \%$ and $57.14 \%$ in Group A, B, C respectively, with myoinositol having better results. ${ }^{27}$ Whereas studies performed by Ranwa $\mathrm{M}$ et al, Genazzani AD et al, Papeleo E et al, treated PCOS cases with myoinositol alone and showed significant improvement i.e. $74.5 \%, 88 \%$ and $100 \%$ respectively in menstrual cycles. $^{30-32}$

Hyperandrogenism results in a variety of cutaneous manifestations as acne, hirsutism, acanthosis nigricans etc; caused by increased LH levels and coexisting insulin resistance contributing to hyperandrogenism. Amongst all the cases with skin manifestations, hirsutism is the most common clinical presentation in the patient recruited in the present study. In this study maximum improvement was seen in Group C with $50 \%$ cases of acne (3/6) and in 10 out of 20 cases $(50 \%)$ of hirsutism. Whereas acne and hirsutism both were improved in $60 \%$ of cases in Group A. But only $20 \%$ of cases with hirsutism and $25 \%$ cases with acne were improved in Group B. This study results were similar to study by Nagaria $\mathrm{T}$ et al, with observed improvement of $66.66 \%$ in cases of acne and $29.4 \%$ in hirsutism cases treated with combination drug. ${ }^{29}$ Ranwa $\mathrm{M}$ et al observed an improvement of only $33.3 \%$ in cases of acne on administration of $2 \mathrm{~g}$ myoinositol per day. ${ }^{30} \mathrm{Le}$ Donne et al, observed significant improvement in hirsutism in cases treated with combination of metformin and myoinositol than metformin alone. ${ }^{33}$

Significant improvement was seen in the post treatment serum LH/FSH ratio $(\mathrm{p}<0.05)$, fasting insulin and HOMA-IR $(\mathrm{p}<0.05)$ and insulin sensitivity in all three groups. HOMA-IR is a measure of insulin resistance and was significantly improved in group treated with combination of metformin and myoinositol $(\mathrm{p}<0.05)$ and metformin alone.

Similar results were seen by study conducted with Nagaria T et al whereas studies conducted by Nehra et al, Angik $\mathrm{R}$ et al showed improvement in insulin sensitivity on metformin treatment. ${ }^{28,29,34}$ It is due to the effect of metformin on hepatic gluconeogenesis, insulin sensitivity, enhance peripheral glucose uptake and decrease glucose absorption from GIT. And in combination group the synergistic action of myoinositol with metformin has resulted in significant reduction in drug dosage, but without affecting the efficacy of drug.

In PCOS cases due to alteration in GnRH pulse frequency there is increased LH level but normal or decreased FSH level. In the present study the decrease in mean LH/FSH values after 24 weeks were measured as $1.13,0.9,1.14$ in Group A, B, C respectively with maximum decrease in Group C followed by Group A. Similar results were observed in various studies. Angik R et al and Nehra et al showed better improvement in group treated with metformin whereas Nagaria $\mathrm{T}$ et al have better results with combination group. ${ }^{28,29,34}$

Infertility is the major concern posed by PCOS due to oligo/anovulation, which needs proper evaluation and management. Poor follicular development leads to failed ovulatory LH surge, hence causing anovulation. Out of all the cases of infertility, $15 / 52(28.8 \%)$ conceived with treatment. The pregnancy rates were highest with combination i.e. $35 \%(n=7)$ followed by with metformin alone i.e. $31.3 \% \quad(n=5)$ and then $18.7 \% \quad(n=3)$ with myoinositol alone.

There was statistically significant improvement in pregnancy rates after 24 weeks of treatment in Group A ( $\mathrm{p}$ value $<0.05)$ and Group $\mathrm{C}(\mathrm{p}$ value $<0.05)$ with greater improvement in group $\mathrm{C}>\mathrm{A}$, whereas the improvement in Group B was not statistically significant (p value $>0.05)$. Similar results were observed by Nagaria $\mathrm{T}$ et al (20\% in combination group), Chirania et al (100\% in combination group), Angik R et al (35\% in metformin group). ${ }^{27-29}$ 


\section{CONCLUSION}

PCOS is the most common endocrine disorder affecting $5-10 \%$ of women in reproductive age group. Hyperinsulinemia is the mainstay of the pathophysiology of PCOS. A decrease in insulin resistance is reflected in terms of clinical and biochemical improvement in PCOS. The synergistic action of myoinositol with metformin has resulted in significant reduction in drug dosage but without affecting the efficacy of drug. Thus, present study concludes that metformin and combination of metformin and myoinositol can be effective in management of cases of PCOS. Though the results of the present study are encouraging but authors are aware of the limitations of the study that the duration and sample size are small. Further research with larger sample size and longer duration of follow-up is needed to support these findings.

Funding: No funding sources

Conflict of interest: None declared

Ethical approval: The study was approved by the Institutional Ethics Committee

\section{REFERENCES}

1. Sirman SM, Pate KA. Epidemiology, diagnosis, and management of polycystic ovary syndrome. Clin Epidemiol. 2013;18(6):1-13.

2. Nidhi R, Padmalata V, Nagarathna R, Amritanshu R. Prevalence of polycystic ovarian syndrome in Indian adolescents. J Pediatr Adolesc Gynecol. 2011;24:223-7.

3. Nivetha M, Susan G. Suganya. Survey of poly cystic ovarian disease (PCOD) among the girl students of bishop Heber College, Trichirapalli, Tamil Nadu, India. IOSR-JNHS. 2016;5(4):44-52.

4. Hoffman, Schorge, Schaffer, Halvorson, Bradshaw, Cunningham. Williams gynaecolgy, $2^{\text {nd }}$ edition, chapter 17; 2012:460-461.

5. Rotterdam ESHRE/ASRM-Sponsored PCOS consensus workshop group. Revised 2003 consensus on diagnostic criteria and long-term health risks related to polycystic ovary syndrome (PCOS). Hum Reprod. 2004;19:41.

6. Gilvaz S, Presannakumari B. PCOS is now recognized to be a very heterogenous condition. Postgraduate Gynaecol. 2011;9:145-9.

7. Tsilchorozidou T, Overton C, Conway GS. The pathophysiology of polycystic ovary syndrome. Clin Endorinol (OXf); 2004:60:17.

8. Sirmans SM, Pate KA. Epidemiology, diagnosis and management of polycystic ovary syndrome. J Epidemiol. 2013:1-13.

9. Papalio E, Vitoriounefer V, Baillargeon JP, Fusi F, Occhi F, De Santis L. Myo-inositol may improve oocyte quality in intracytoplasmic sperm injection cycles. A prospective, controlled, randomized trial. Metabol Clin Exper. 1999;48(2):167-17.
10. Hull MG. Epidemiology of infertility and polycystic ovarian disease: endocrinological and demographic studies. Gynecol Endocrinol. 1987;1:235-45.

11. Franks S, McCarthy MI, Hardy K. Development of polycystic ovary syndrome: involvement of genetic and environmental factors. Int $J$ Androl. 2006;29:278-85.

12. Liang SJ, Liou TH, Lin HW, Hsu CS, Tzeng CR, Hsu MI. Obesity is the predictor of impaired glucose tolerance and metabolic disturbance in polycystic ovary syndrome. Acta Obstet Gynecol Scand. 2012;91(10):1167-72.

13. Fritz MA, Speroff L. Clinical Gynecologic Endocrinology and Infertility, $8^{\text {th }}$ edition (Lippincott Williams and Wilkins; 2010:505.

14. Ravn P, Haugen AG, Glintborg D. Overweight in polycystic ovary syndrome. An update on evidencebased advice on diet, exercise and metformin use for weight loss. Minerva Endocrinol. 2013;38(1):59-76.

15. Lujan ME, Chizen DR, Pierson RA. Diagnostic criteria for polycystic ovary syndrome: pitfalls and controversies. J Obstet Gynaecol Can. 2008;30(8):671-9.

16. Al-Inany H, Johnson N. Drugs for anovulatory infertility in polycystic ovary syndrome. BMJ. 2006;332:1461-2.

17. Nordio M, Proietti E. The combined therapy with myo-inositol and D-chiro-inositol reduces the risk of metabolic disease in PCOS overweight patients compared to myo-inositol supplementation alone. Eur Rev Med Pharmacol Sci. 2012;16(5):575-81.

18. Gerli S, Papaleo E, Ferrari A, di Renzo GC. Randomized, double blind placebo-controlled trial: effects of Myo-inositol on ovarian function and metabolic factors in women with PCOS. Eur Rev Med Pharmacol Sci. 2007;11(5):347-54.

19. Misra A, Chowbey P, Makkar BM, Vikram NK, Wasir JS, Chadha D, et al. Consensus statement for diagnosis of obesity, abdominal obesity and the metabolic syndrome for Asian Indians and recommendations for physical activity, medical and surgical management. J Assoc Physicians India. 2009;57:163-70.

20. Albareda M, Rodríguez-Espinosa J, Murugo M, deLeyva A, Corcoy R. Assessment of insulin sensitivity and $\beta$-cell function from measurements in the fasting state and during and oral glucose tolerance test. Diabetol. 2000;43:1507-11.

21. Momin AA, Bankar MP, Bhoite GM. Determination of HOMA IR cut off value, and efficiency of lipids and lipoprotein ratios as discriminator of insulin resistance in type 2 diabetes mellitus patients. IOSR J Pharma. 2014;4(6):9-14.

22. Radwan M, Youssry MA, El-saadany HM. Evaluation of different biochemical markers in prediction of metabolic syndrome in polycystic ovary syndrome patients. Int J Reprod Contracept Obstet Gynecol. 2017;6(7):2734-40.

23. Muniyappa R, Lee S, Chen H, Quon MJ. Current approaches for assessing insulin sensitivity and 
resistance in vivo: advantages, limitations, and appropriate usage. Am J Physiol Endocrinol Metab. 2008;294:15-26.

24. Minozzi M, Nordio M, Pajalich R. The combined therapy myo-inositol plus D-chiro-inositol, in a physiological ratio, reduces the cardiovascular risk by improving the lipid profile in PCOS patients. Age. 2013;26:5-1.

25. Nehra J, Kaushal J, Singhal SR, Ghalaut VS. A comparative study of efficacy and safety of myoinositol versus metformin in polycystic ovarian syndrome in women. World J Pharma Pharmaceut Sci. 2016;5(5):884-96.

26. $\mathrm{Hu} \mathrm{L}$, Shen H, Wu QF, Tian L, Hu MH. Treatment of polycystic ovarian syndrome with insulin sensitizer. Clin Exp Obstet Gynaecol. 2014;41:28892.

27. Chirania K, Misra S, Behera S. A randomized clinical trial comparing myoinositol and metformin in PCOS. Int J Reprod Contracept Obstet Gynecol. 2017;6:1814-20.

28. Angik R, Jajoo SS, Hariharan C, Chimote A. A comparative study of metabolic and hormonal effects of myoinositol vs. metformin in women with polycystic ovary syndrome: a randomised controlled trial. Int J Reprod Contracept Obstet Gynecol. 2017;4(1):189-4.

29. Nagaria T, Mohapatra A, Jaiswal J. Effect of myoinositol and metformin in combination on clinical and hormonal profile in patients of polycystic ovarian syndrome. Int $\mathrm{J}$ Reprod Contracept Obstet Gynecol. 2019;8(2):703.

30. Ranwa M, Nagaria T, Jaiswal J, Arya A. Study of effect of myoinositol on menstrual irregularities and skin problems in polycystic ovarian syndrome cases.
Int J Reprod Contracept Obstet Gynecol. 2017;6(6):2310-7.

31. Genazzani AD, Lanzoni C, Ricchieri F, Jasonni VM. Myo-inositol administration positively affects hyperinsulinemia and hormonal parameters in overweight patients with polycystic ovary syndrome. Gynecol Endocrinol. 2008;24:139-44.

32. Papaleo E, Unfer V, Baillargeon JP, De Santis L, Fusi F, Brigante C, et al. Myo-inositol in patients with polycystic ovary syndrome: a novel method for ovulation induction. Gynecol Endocrinol. 2007;23(12):700-3.

33. Le Donne M, Alibrandi A, Giarrusso R, Lo MI, Muraca U. Diet, metformin and inositol in overweight and obese women with polycystic ovary syndrome: effects on body composition. Minerva Ginecol. 2012;64(1):23.

34. Nehra J, Kaushal J, Singhal SR, Ghalaut VS. A comparative study of myo inositol versus metformin on biochemical profile in polycystic ovarian syndrome in women. Int $\mathbf{J}$ Pharma Sci Res. 2017;8(4):1664.

Cite this article as: Thakur SS, Anjum S, Siddiqui SS. Randomised controlled trial: comparing effects of metformin versus myoinositol versus metformin and myoinositol on ovarian functions and metabolic factors in polycystic ovarian syndrome. Int J Reprod Contracept Obstet Gynecol 2020;9:2542-9. 